\title{
Reversible occlusion of donor vessel caused by mouth opening after superficial temporal artery-middle cerebral artery anastomosis in adult moyamoya patients
}

\author{
Toshiro Katsuta, MD, Hiroshi Abe, MD, Koichi Miki, MD, and Tooru Inoue, MD \\ Department of Neurosurgery, Faculty of Medicine, Fukuoka University, Fukuoka, Japan
}

OBJECT The authors experienced an intriguing phenomenon in 2 adult patients with moyamoya disease. Mouth opening caused reversible occlusion of the donor superficial temporal artery (STA), and the patients exhibited transient cerebral ischemic symptoms. The aim of this study was to assess the incidence of such occlusion and the mechanism of this phenomenon.

METHODS Twelve consecutive adult patients with moyamoya disease (15 affected sides) who underwent STA-middle cerebral artery anastomosis were included in this study. Ultrasound examination was performed more than 3 months postoperatively to determine whether mouth opening affected blood flow of the donor STA and led to any ischemic symptoms within 1 minute. Computed tomography angiography was performed during both mouth opening and mouth closing, when blood flow changes of the donor STA were recognized.

RESULTS Under wide mouth opening, steno-occlusion of the donor STA occurred in 5 of 15 sides (33.3\%). On 1 side $(6.7 \%)$, complete occlusion induced ischemic symptoms. Steno-occlusion occurred by at least 2 mechanisms: either the stretched temporalis muscle pushed the donor STA against the edge of the bone window, or the redundant donor STA kinked when the muscle was stretched.

CONCLUSIONS Even with temporary occlusion of the donor STA, ischemic symptoms seem to rarely occur. However, to avoid the "big bite ischemic phenomenon," the authors recommend securing a sufficient distance between the donor STA and the edge of the bone window and avoiding a redundant course of the donor STA within the muscle layer. http://thejns.org/doi/abs/10.3171/2014.10.JNS141805

KEY WORDS extracranial-intracranial bypass; mouth opening; occlusion; superficial temporal artery; temporalis muscle; moyamoya disease; vascular disorders

$\mathrm{T}$ HE results of an extracranial-intracranial bypass study $^{1}$ in 1985 were discouraging. Likewise, use of superficial temporal artery (STA)-middle cerebral artery (MCA) bypass surgery for atherosclerotic steno-occlusive disease was denied based on its poor efficacy in a randomized trial ${ }^{12}$ in 2011. Nevertheless, the usefulness of STA-MCA anastomosis for moyamoya disease has been taken for granted for a long period of time. ${ }^{5}$ Because the STA runs superficial to the temporalis muscle, it should be introduced to the cerebral surface by either perforating the muscle layer or by diversion around the muscle. We experienced a curious phenomenon in 2 adult patients with moyamoya disease: mouth opening caused reversible occlusion of the donor STA, and the patients exhibited transient symptoms of cerebral ischemia. In the present study, the incidence and mechanism of such occlusion were investigated in a group of patients, and techniques for avoiding this phenomenon are proposed.

\section{Methods}

Thirty-six patients with moyamoya disease ( 55 affected sides) underwent direct and/or indirect bypass surgery at Fukuoka University Hospital from August 2008 to July

ABBREVIATIONS CTA = computed tomography angiography; $\mathrm{EMS}=$ encephalomyosynangiosis; $\mathrm{MCA}=$ middle cerebral artery; STA = superficial temporal artery . SUBMITTED August 5, 2014. ACCEPTED October 20, 2014.

INCLUDE WHEN CITING Published online April 24, 2015; DOI: 10.3171/2014.10.JNS141805.

DISCLOSURE The authors report no conflict of interest concerning the materials or methods used in this study or the findings specified in this paper. 
2013. Among them, adult patients ( $>17$ years of age) who underwent surgery including STA-MCA anastomosis (with or without indirect bypass) were selected for this investigation. Twelve consecutive patients (15 affected sides) were included. Ultrasound examination was performed more than 3 months after surgery to determine whether mouth-opening movement affected blood flow of the donor STA. At the same time, the patients were monitored if mouth-opening movement led to any ischemic symptoms within 1 minute. The mouth was maximally opened until the mandibular condyle subluxated anteriorly. A $>50 \%$ reduction in the mean flow velocity of the STA was defined as stenosis, and a $>90 \%$ reduction was defined as occlusion. Computed tomography angiography (CTA) was performed both under mouth-opening and -closing conditions when steno-occlusive change was detected. The thickness of the temporal squama close to the inlet of the donor STA was also measured. In addition to this study group, CTA was performed in another adult patient with moyamoya disease who exhibited ischemic symptoms upon mouth opening (Case A; the operation was performed by the first author at another institute).

Statistical analysis was performed between the 2 groups: the group in which mouth opening does not affect the donor STA flow and the other group, in which flow change was observed. The Mann-Whitney U-test was used for factors of age at operation, donor STA diameter, and bone thickness at the inlet of the donor STA. Fisher's exact test was used for sex, side of operation, preoperative presentation, and surgical procedures. A $\mathrm{p}$ value $<0.05$ was considered statistically significant.

\section{Results}

The patients' data are listed in Table 1. The patency of the direct bypass had been confirmed before the study in each patient and affected side. The patency of at least 1 donor vessel had been confirmed in cases of double bypass. One side in 1 patient exhibited complete occlusion of the donor STA upon mouth opening, leading to ischemic symptoms (Case 12). Decreased bypass flow was found in 1 side in each of 4 patients, and none of them were symptomatic. No changes in the bypass flow were noted in the other 10 affected sides. As a result, mouth opening affected bypass flow in 5 of the 15 affected sides (33.3\%). Occlusion occurred in 1 side $(6.7 \%)$ and led to ischemic symptoms. In 4 of the 5 sides in which the bypass flow was affected, both echography and CTA showed that stenoocclusion was caused by compression of the STA against the edge of the bone window. In 1 side, a redundant STA developed kinking in the muscle layer upon maximal mouth opening.

\section{Illustrative Cases}

Case 11 (Asymptomatic Stenosis)

A 50-year-old man with a history of left encephalomyoarteriosynangiosis underwent a right STA-MCA single anastomosis. The procedure was not combined with indirect bypass. The postoperative course was uneventful. Although the patient was asymptomatic upon mouth opening, ultrasound revealed reduction of the donor STA flow.
CTA demonstrated a redundant course of the donor STA upon mouth closing and kinking of the donor STA upon mouth opening (Fig. 1).

\section{Case 12 (Symptomatic Occlusion)}

A 40-year-old man underwent a left STA-MCA single bypass for misery perfusion of the left hemisphere. The temporalis muscle was dissected in an inverted-T fashion, and the donor STA was introduced between the 2 muscle pieces. Each muscle piece was further split into 2 layers; the deeper layer was used for encephalomyosynangiosis (EMS) to complete the combined bypass, and the superficial layer was used to cover the bone flap. The postoperative course was uneventful, and the patient was discharged after patency of the STA-MCA anastomosis had been confirmed by ultrasound and CTA. Approximately 2 weeks postoperatively, the patient reported numbness in his right arm when he opened his mouth widely while eating meals, yawning, and brushing his teeth. The numbness developed several seconds after mouth opening and subsided immediately after mouth closing. Continuous mouth opening resulted in shaking of the right hand, which was similar to his initial symptom before treatment. Numbness was also induced by resting his left cheek on his left hand. He experienced shaking of his right arm while visiting a dentist, necessitating frequent pauses during treatment. CTA revealed that the STA was occluded at the edge of the bone window upon mouth opening (Fig. 2).

\section{Case A (Symptomatic Occlusion, Not Included in Study Group)}

Left STA-MCA double anastomosis in a 45 -year-old man with moyamoya disease and a history of an ischemic event was performed by the first author in another institute. The temporalis muscle was incised in the shape of the number 7 to preserve as many muscle fibers as possible. No indirect methods were added to the procedure. The postoperative course was uneventful, and examination revealed patency of both anastomoses. One month postoperatively, the patient began to notice numbness in the right hand when he opened his mouth widely. The numbness began immediately after wide mouth opening and subsided about 30 seconds after mouth closing. Masticatory movements did not induce numbness. However, the patient experienced numbness when resting his left cheek on his left hand. CTA was first performed with the mouth open and then with the mouth closed. The donor STA was not filled beyond the level of the root of the zygoma when the mouth was open, indicating a complete occlusion; it was filled after mouth closing, showing good patency of the anastomosis (Fig. 3).

\section{Discussion}

Only a single report on the effects of mouth opening on donor vessels after bypass surgery exists in the literature. In that report, the authors described reversible steno-occlusion in 3 patients with moyamoya disease. ${ }^{3}$ The mechanism and incidence of this phenomenon had not yet been clarified. The present investigation showed that mouth opening affected bypass flow in $33.3 \%$ of sides affected by moyamoya disease and that occlusion occurred in $6.7 \%$ 


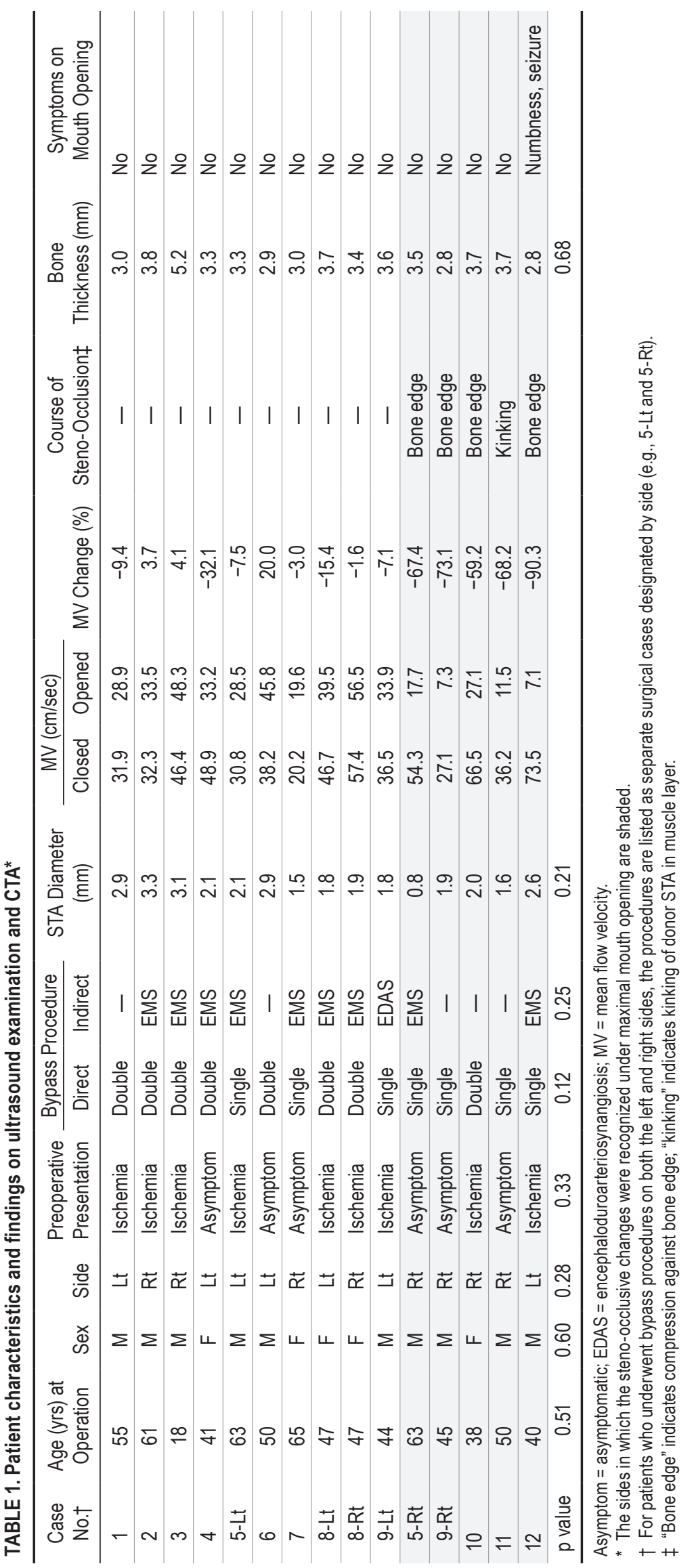



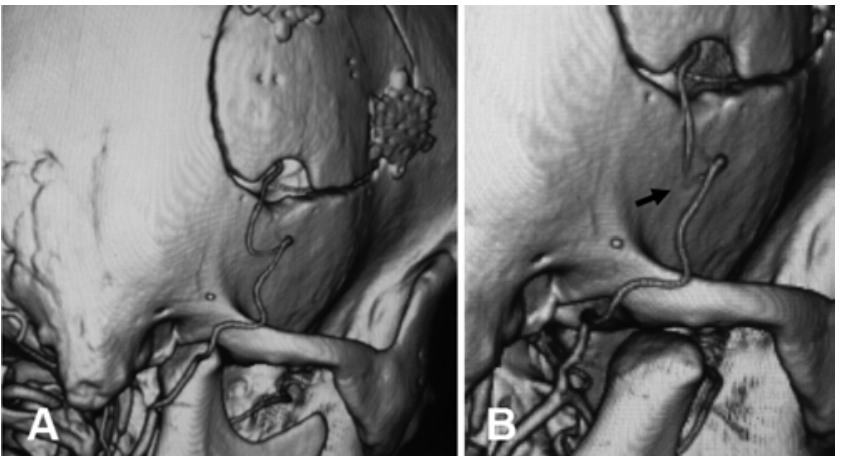

FIG. 1. Case 11. Postoperative 3D CTA. A: The donor STA exhibits a redundant course in the muscle layer with mouth closing. B: Kinking of the donor STA (arrow) occurs upon wide mouth opening.

of affected sides, leading to ischemic symptoms. Because this study was planned after we experienced Case 12 in our institute (i.e., this study started with a positive case), the results undoubtedly include a certain bias. The incidence of steno-occlusion or ischemic symptoms might be lower in a wider population. Furthermore, the details of the procedure of bypass surgery differ among institutes as well as among surgeons. The incidences found in the present study should not be considered universal but a rough standard.

Several patients in this study exhibited asymptomatic stenosis of the donor STA. Freyschlag et al. suggested that asymptomatic steno-occlusion might occur with a

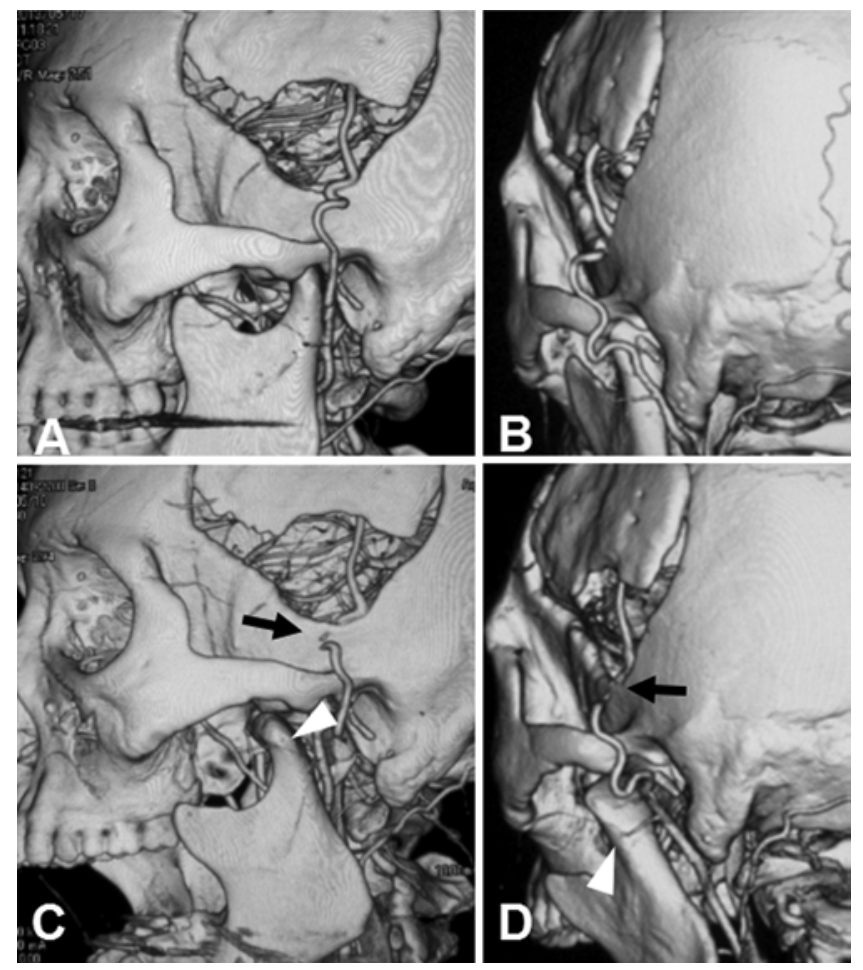

FIG. 2. Case 12. 3D CTA reconstructions obtained 3 years after bypass surgery while the patient's mouth was closed ( $A$ and $B$ ) and while it was open ( $C$ and $\mathbf{D}$ ). The mouth is opened until the mandibular condyle subluxates anteriorly (white arrowhead). The donor STA is occluded at the edge of the bone window (black arrow).

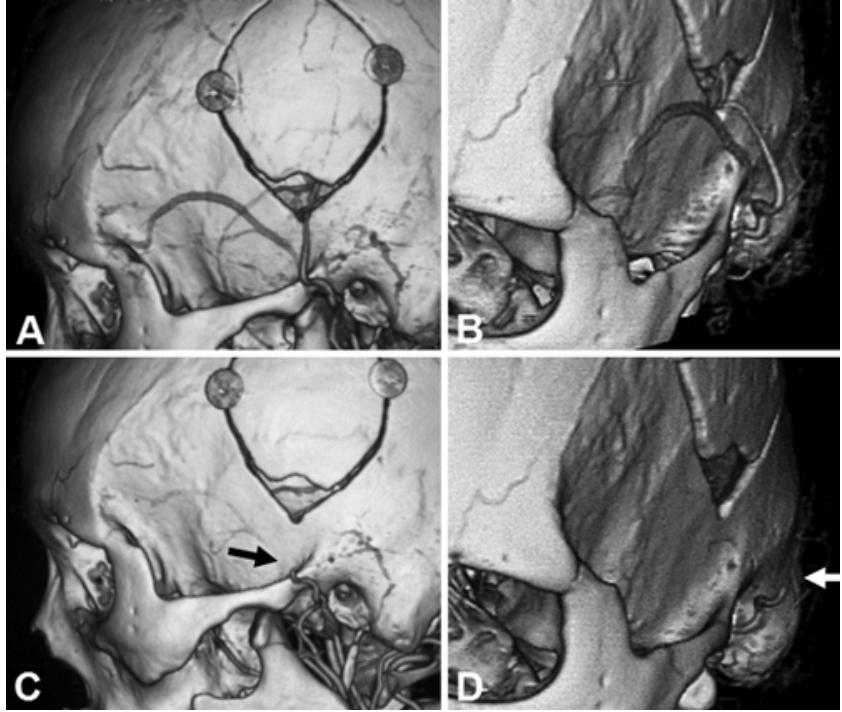

FIG. 3. Case A. 3D CTA reconstructions obtained 3 months after surgery. A and B: With the mouth closed, the donor STA is completely filled and courses very close to the bone edge. C and D: Imaging obtained with the patient's mouth open was examined prior to mouth closing. Filling of the contrast medium stops at the level of the root of the zygoma (black and white arrows), indicating that the obstruction is located somewhere between the root of the zygoma and the anastomosis.

well-developed indirect bypass. ${ }^{3}$ Alternatively, according to previous studies ${ }^{2,4,6-9}$ in which the intended donor STA occlusion was performed by manual compression after STA-MCA bypass, ischemic symptoms were rarely seen (Table 2). Although most patients in these studies seemed to have atherosclerotic steno-occlusion, complete occlusion is not necessarily symptomatic (or rather, is rarely symptomatic), even if no indirect support is present. Theoretically, the demand of the bypassed hemisphere will play an important role in this ischemic phenomenon. Namely, the presence of preoperative ischemic events along with a well-developed donor STA, carrying abundant blood, may predict the occurrence of this phenomenon; in fact, our data are not incompatible with this theory, although statistical analysis failed to extract any significant factors in this study with a small number of patients. In Cases 12 and A, the patients' resting their cheeks on their hands must have induced a condition similar to that of a manual compression test.

Anterior subluxation of the mandibular condyle from the glenoid fossa, together with the hinge movement, enables the mouth to open as wide as $5 \mathrm{~cm}^{10,11}$ The mean amount of anterior dislocation of the condyle is about 18 $\mathrm{mm} .{ }^{10}$ The temporalis muscle, which is attached to the coronoid process of the mandible, is fully stretched in a passive manner. This movement of the temporalis muscle can cause distortion of the donor STA, which pierces the muscle layer. Freyschlag et al. $^{3}$ guided the donor artery directly through the fibers of the EMS, instead of diverting it around the muscle, and speculated that obstruction might be induced by stretched muscle fibers under mouth opening. In 4 patients, CTA revealed that the steno-occlusion took place at the edge of the bone window. We estimate that the stretched muscle flap pushed the donor 
TABLE 2. Studies using manual compression of the donor STA

\begin{tabular}{|c|c|c|c|c|}
\hline Authors \& Year & $\begin{array}{l}\text { No. of } \\
\text { Cases }\end{array}$ & $\begin{array}{l}\text { Occlusion } \\
\text { Time }\end{array}$ & $\begin{array}{l}\text { Ischemic } \\
\text { Symptom }\end{array}$ & Measurement \\
\hline $\begin{array}{l}\text { Matsumoto \& } \\
\text { Shichijo, } 1983\end{array}$ & 17 & $10 \mathrm{~min}$ & 3 & EEG \\
\hline Hyodo et al., 1983 & 10 & $5 \mathrm{~min}$ & 0 & $\begin{array}{c}\text { EEG \& carotid } \\
\text { blood flow }\end{array}$ \\
\hline $\begin{array}{l}\text { Elsenburg et al., } \\
1985\end{array}$ & 40 & NA & NA & $\begin{array}{l}\text { Ophthalmic ar- } \\
\text { tery pressure }\end{array}$ \\
\hline Kubo, 1986 & 30 & $4.5 \mathrm{~min}$ & NA & $\begin{array}{l}\text { Cerebral blood } \\
\text { flow }\end{array}$ \\
\hline $\begin{array}{l}\text { Nakamura \& } \\
\text { Iwata, } 2000\end{array}$ & 45 & $30 \mathrm{sec}$ & NA & EEG \\
\hline Murata et al., 2003 & 30 & $30-100 \mathrm{sec}$ & 0 & $\begin{array}{r}\text { Cerebral blood } \\
\text { oxygenation }\end{array}$ \\
\hline
\end{tabular}

EEG = electroencephalography; $\mathrm{NA}=$ not applicable.

STA against the bone edge regardless of whether EMS was adopted. In Case A, the occlusion point could not be determined because the donor STA was not completely filled with contrast medium. However, because the donor STA coursed very close to the bone edge, a similar compression mechanism is thought to have occurred. We thought that the bone thickness at the inlet of the donor STA might have had an influence. However, statistical analysis revealed no relationships between the bone width and likelihood of steno-occlusion.

In Case 11, redundancy of the donor artery led to its kinking when the muscle was stretched. The present study revealed at least 2 different mechanisms of steno-occlusion: 1) compression of the donor STA against the edge of the bone window and 2) kinking of the redundant donor (Fig. 4). To avoid brain ischemia upon mouth opening, we recommend securing a sufficient distance between the donor STA and the edge of the bone window and adjusting the length of the donor STA in the muscle layer. Having the anesthesiologist open the patient's mouth while testing the blood flow might also be an effective option.

In Cases 12 and $\mathrm{A}$, complete occlusion upon mouth opening led to ischemic symptoms. Both patients report no other difficulties in their daily lives because the symptoms occur only with wide mouth opening; other mouth movements such as chewing or speaking do not bother them. However, if continuous wide mouth opening is required, as when undergoing dental treatment, a critical situation might ensue. Furthermore, severe brain ischemia might develop during treatment under general anesthesia. If needed, rongeuring of the edge of the bone window might be proposed in our patients because the donor STA is compressed against the window in both cases.

\section{Conclusions}

Steno-occlusion of the donor STA occurred upon wide mouth opening in 5 of 15 affected sides (33.3\%) in adult patients with moyamoya disease who had undergone STAMCA anastomosis. Complete occlusion induced ischemic symptoms in 1 side (6.7\%). This study revealed at least 2 steno-occlusive mechanisms: 1) the stretched temporalis muscle fibers push the donor STA against the edge of the bone window, and 2) the redundant donor STA kinks

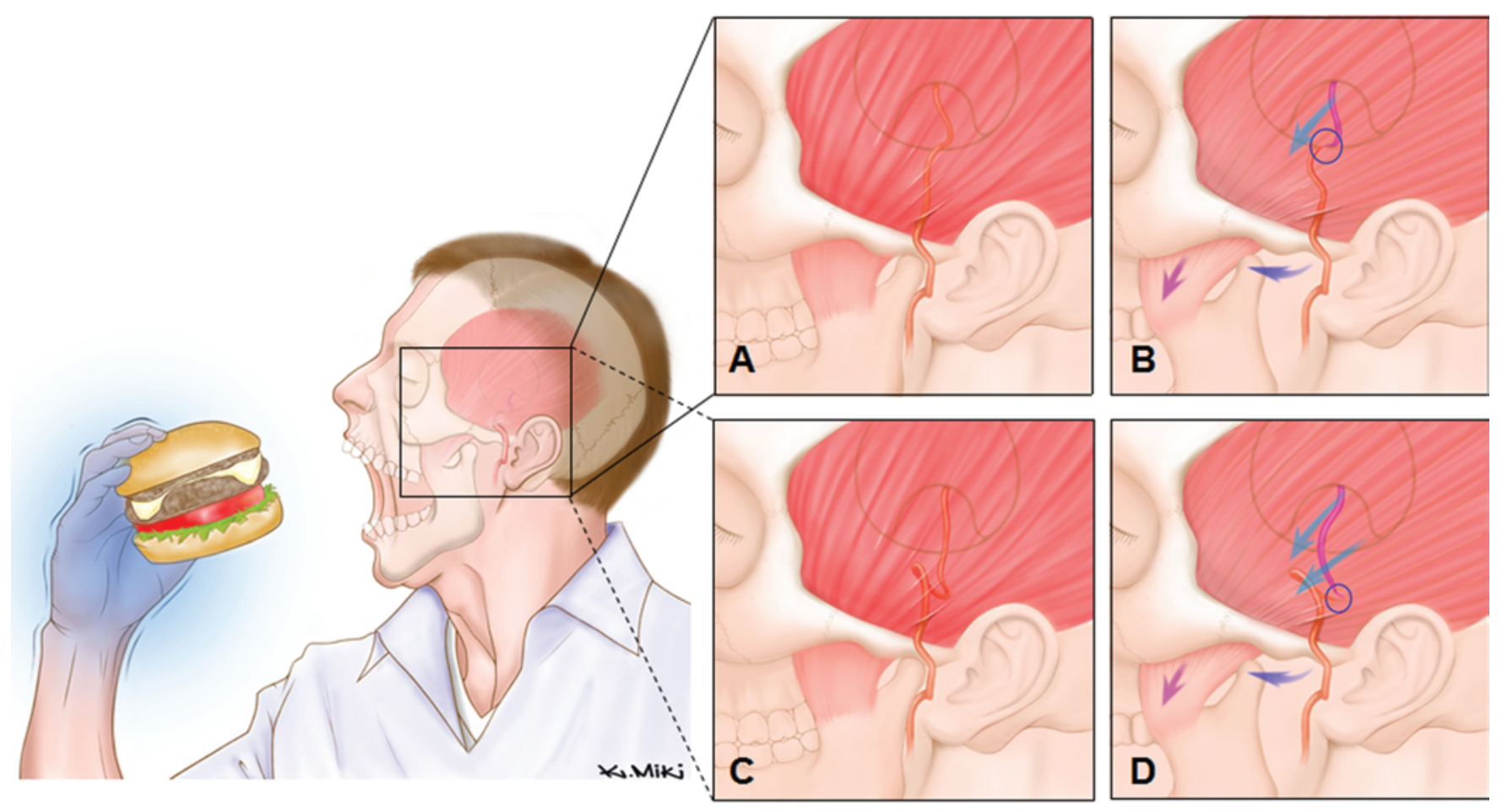

FIG. 4. Artist's impression of the 2 types of "big bite ischemic phenomenon." $\mathbf{A}$ and B: The donor artery is compressed against the bone edge. $\mathrm{C}$ and $\mathrm{D}$ : The redundant donor artery is kinked within the muscle layer. Copyright Koichi Miki. Published with permission. 
when the muscle is stretched. Even if the donor STA is temporarily occluded, ischemic symptoms seem to rarely occur as a consequence. To avoid the "big bite ischemic phenomenon," we recommend securing a sufficient distance between the donor STA and the edge of the bone window and avoiding a redundant course of the donor STA within the muscle layer.

\section{Acknowledgments}

The authors thank Hirofumi Shimada for his great help in the ultrasound examination and Toshiyasu Ogata, M.D., for statistical analysis.

\section{References}

1. EC/IC Bypass Study Group: Failure of extracranial-intracranial arterial bypass to reduce the risk of ischemic stroke. Results of an international randomized trial. N Engl J Med 313:1191-1200, 1985

2. Elsenburg PH, Overtoom TT, Eikelboom BC, Tulleken CA: Ophthalmopneumoplethysmography (OPG-Gee) without and with bypass-compression for quantification of hemodynamic significance of superficial temporal artery-middle cerebral artery (STA-MCA) anastomosis. Clin Neurol Neurosurg 87:259-266, 1985

3. Freyschlag CF, Seiz M, Brockmann MA, Scharf J, Stier RW, Schubert GA, et al: Effect of mouth opening on bypass function after combined revascularization for Moyamoya disease. Acta Neurochir Suppl 112:35-38, 2011

4. Hyodo A, Mizukami M, Kawase T, Nagata K, Yunoki K, Yamaguchi K: [Postoperative evaluation of extracranialintracranial (EC/IC) arterial bypass using ultrasonic quantitative flow measurement (UQFM) and the computed mapping of EEG (CME).] No Shinkei Geka 11:627-633, 1983 (Jpn)

5. Karasawa J, Kikuchi H, Furuse S, Kawamura J, Sakaki T: Treatment of moyamoya disease with STA-MCA anastomosis. J Neurosurg 49:679-688, 1978

6. Kubo N: [A study of regional cerebral blood flow before and after superficial temporal artery-to-middle cerebral artery anastomosis.] No Shinkei Geka 14:1547-1556, 1986 (Jpn)

7. Matsumoto K, Shichijo F: [Functional grading of the efficacy of STA-MCA anastomosis examined by dynamic topography(serial two-dimensional EEG mapping).] Geka Chiryo 49:600-601, 1983 (Jpn)
8. Murata Y, Katayama Y, Sakatani K, Fukaya C, Kano T: Evaluation of extracranial-intracranial arterial bypass function by using near-infrared spectroscopy. J Neurosurg 99:304-310, 2003

9. Nakamura T, Iwata Y: [Postoperative evaluation of EC/IC bypass surgery-long-term follow up study by donor artery compression test.] No Shinkei Geka 28:1057-1062, 2000 (Jpn)

10. Obwegeser HL, Farmand M, Al-Majali F, Engelke W: Findings of mandibular movement and the position of the mandibular condyles during maximal mouth opening. Oral Surg Oral Med Oral Pathol 63:517-525, 1987

11. Park JT, Lee JG, Won SY, Lee SH, Cha JY, Kim HJ: Realization of masticatory movement by 3-dimensional simulation of the temporomandibular joint and the masticatory muscles. J Craniofac Surg 24:e347-e351, 2013

12. Powers WJ, Clarke WR, Grubb RL Jr, Videen TO, Adams HP Jr, Derdeyn CP: Extracranial-intracranial bypass surgery for stroke prevention in hemodynamic cerebral ischemia: the Carotid Occlusion Surgery Study randomized trial. JAMA 306:1983-1992, 2011

\section{Author Contributions}

Conception and design: Katsuta. Acquisition of data: Katsuta, Abe. Analysis and interpretation of data: Katsuta. Drafting the article: Katsuta. Critically revising the article: Katsuta, Inoue. Reviewed submitted version of manuscript: Inoue. Approved the final version of the manuscript on behalf of all authors: Katsuta. Statistical analysis: Katsuta. Administrative/technical/material support: Abe, Miki. Study supervision: Inoue. Illustrator: Miki.

\section{Supplemental Information \\ Previous Presentation}

Portions of this work were presented in abstract form at the 43rd meeting of the Japanese Society on Surgery for Cerebral Stroke, Osaka, Japan, on May 15, 2014.

\section{Correspondence}

Toshiro Katsuta, Department of Neurosurgery, Faculty of Medicine, Fukuoka University, 7-45-1 Nanakuma, Jonan-ku, Fukuoka 814-0180, Japan. email: tktktk010101@m3.dion.ne.jp. 